\title{
Surgical management and recurrence of pterygium at indus medical college hospital and mohammad Al- Dossary hospital
}

\begin{abstract}
Purpose: To evaluate and compare the results of our technique with other common techniques used for the management of pterygium.

Materials and methods: 33eyes of 30patients included in this study for the surgical management of pterygium. Out of 33 eyes, 12(40\%) were right eyes, 15(50\%) were left eyes and $3(10 \%)$ were both eyes (Table 1), all were male (Table 2), 10(33.33\%) belong to age group A, $11(36.66 \%)$ belong to age group B and $9(30 \%)$ patients belong to age group C. (Table 3). All being operated for excision of pterygia under local anesthesia using $2 \%$ lidocaine after aseptic techniques, drapping and using 2 drops of $10 \%$ povidone solution instilled into eye, after 1minute copious irrigation done. All were undergone simple pterygium excision under local anesthesia ( $2 \%$ lidocaine injection), $1 / 2$ cc lidocaine injected subconjunctivally as well as topical alcaine eye drops were used before and during surgery. Excision of pterygium done using conjunctival scissors, 15 no blade being used for anterior keratectomy. We used simple excision of pterygium with scrapping of cornea and advancement of conjunctiva up to $1 \mathrm{~mm}$ behind the limbal area using 2 sutures of $8 / 0$ vicryl. Patients were followed with daily dressings till corneal stain become negative, and then allowed drops i.e sodium hyaluronate $2 \%$ 4hourly along with steroid antibiotic combination 6 hourly. Patients followed weekly for one month, monthly for 3 months, then after every six months.
\end{abstract}

Results: Out of 33 only $2(6.06 \%)$ patients suffered with recurrence reason was poor compliance regarding the use of medicines (Table 4). One got recurrence after 3 months and other after 8 months. 31 eyes were not shown any recurrence up till now.

Conclusion: Despite different management options are available but we found this technique (simple pterygium excision with advancement of conjunctiva) was very simple, easy and time saving with very less chances of recurrence.

Keywords: Khan Na, Khan Aa Memon J et al., Indus medical college hospital tando m khan, Pakistan/Mohammad Al-Dossary Hospital, Khobar, KSA, Pterygium in the conjunctiva
Volume 6 Issue 2 - 2017

\author{
Nisar Ahmed Khan, ${ }^{1,2}$ Aftab Ahmed Khan,' \\ Jawaid Iqbal Memon' \\ 'Indus medical college, Hospital Tando Mohammad Khan, \\ Pakistan \\ ${ }^{2}$ Mohammad Al Dossary hospital Khobar, Saudi Arabia
}

Correspondence: Nisar Ahmed Khan Assistant professor, consultant ophthalmologist Indus Medical College, Hospital Tando Mohammad Khan, Pakistan Mohammad Al Dossary Hospital Khobar, Saudi Arabia, Tel +92-300-3014168, Email nisargh200I@yahoo.com

Received: December 20, 2016 | Published: February 7, 2017

\section{Introduction}

Pterygium is a benign growth of the conjunctiva, commonly grows from the nasal side of the conjunctiva, usually present in the palpebral fissure. It is associated with and thought to be caused by ultravioletlight exposure (e.g., sunlight). ${ }^{1,2}$, low humidity, and dust. ${ }^{3-5}$ is characterized by elastotic degeneration of collagen (actinic elastosis) ${ }^{6}$ and fibrovascular proliferation. The exact cause is unknown but it is associated with excessive exposure to wind, sunlight, or sand. Therefore, it is more likely to occur in populations that inhabit the areas near the equator, as well as windy locations. In addition, pterygia are twice more likely to occur in men than women. Some research also suggests a genetic predisposition due to an expression of vimentin, which indicates cellular migration by the keratoblasts embryological development, which are the cells that give rise to the layers of the cornea. Supporting this fact is the congenital pterygium, in which pterygium is seen in infants. These cells also exhibit an increased P53 expression likely due to a deficit in the tumor suppressor gene. These indications give the impression of a migrating limbus because the cellular origin of the pterygium is actually initiated by the limbal epithelium. ${ }^{7}$
Pterygium (conjunctiva) can be diagnosed without need for a specific exam, however corneal topography is a practical test (technique) as the condition worsens. ${ }^{8,9}$ As it is associated with excessive sun ${ }^{10}$ or wind exposure, wearing protective sunglasses with side shields and/or wide brimmed hats and using artificial tears throughout the day may help prevent their formation or stop further growth. Surfers and other water-sport athletes should wear eye protection that blocks $100 \%$ of the UV rays from the water, as is often used by snow-sport athletes. Many of those who are at greatest risk of pterygium from work or play under sun exposure do not understand the importance of protection. ${ }^{11}$ Historically a variety of options is available for the management of pterygium, from irradiation, to conjunctival auto-grafting or amniotic membrane transplantation, along with glue and suture application. Treatments and techniques have evolved and improved due to research and a deeper understanding of pterygium, resulting in some treatments being discontinued.

\section{Material and methods}

33eyes of 30patients included in this study to evaluate the outcome and recurrence after surgical excision of pterygia during January 2014 
to December 2015. We excluded those patients having any history of trauma, burn, chemical exposure, conjunctival degeneration except pterygia (Figure 1). Out of 33 eyes, 12(40\%) were right eyes, $15(50 \%)$ were left eyes and $3(10 \%)$ were both eyes (Table 1), all were male (Table 2), 10(33.33\%) belong to age group A, 11(36.66\%) belong to age group B and $9(30 \%)$ patients belong to age group C (Table 3). All being operated for excision of pterygia under local anesthesia (2\% lidocaine) after aseptic techniques, draping and using 2drops of $10 \%$ povidone solution instilled into eye, after 1 minute copious irrigation done. All were undergone simple pterygium excision under local anesthesia ( $2 \%$ lidocaine injection), $1 / 2$ cc lidocaine injected subconjunctivally as well as topical alcain eye drops were used before and during surgery.
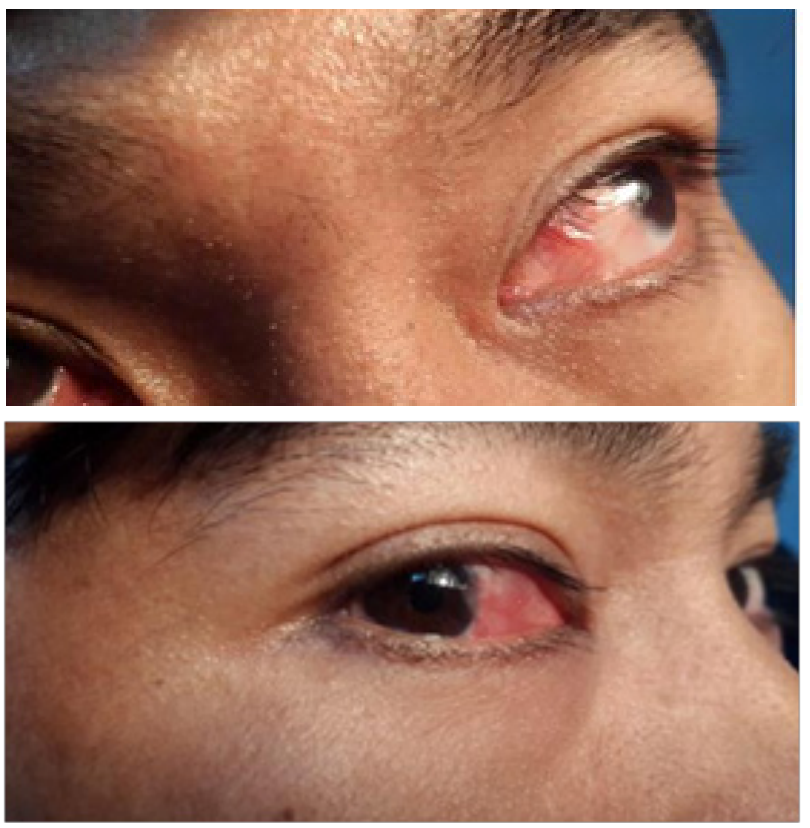

Figure I Patient with bilateral pterygia.

Table I Both eyes

\begin{tabular}{llll}
\hline S. no & Laterality & No of patients & Percentage\% \\
\hline I & Right Eye & I2 & $40 \%$ \\
2 & Left Eye & 15 & $50 \%$ \\
3 & Both Eyes & 3 & $10 \%$ \\
\hline
\end{tabular}

Table 2 All were male

\begin{tabular}{llll}
\hline S. no & Gender & No & Percentage $\%$ \\
\hline I & Male & 30 & $100 \%$ \\
2 & Female & 0 & $0 \%$
\end{tabular}

Table 3 I0(33.33\%) belong to age group A, I I (36.66\%) belong to age group $B$ and $9(30 \%)$ patients belong to age group $C$

\begin{tabular}{llll}
\hline Age groups & Ages & No of patients & Percentage\% \\
\hline A & $20-30 y r s$ & 10 & $33.33 \%$ \\
B & $31-40 y r s$ & 11 & $36.66 \%$ \\
C & $41-50 y r s$ & 9 & $30 \%$ \\
\hline
\end{tabular}

Excision of pterygium done using conjunctival scissors, $15 \mathrm{no}$ blade being used for anterior keratectomy. I used simple excision of pterygium with scrapping of cornea and advancement of conjunctiva up to $1 \mathrm{~mm}$ behind the limbal area using 2sutures of 8/0vicryl. Patients were followed with daily dressings till corneal stain become negative, and then allowed drops i.e sodium hyaluronate $2 \%$ 4hourly along with steroid antibiotic combination 6 hourly. Patients followed weekly for one month, monthly for 3 months, then after every six months. We did not use any scleral cautry, mitomycin C (MMC), grafting of conjunctiva, only relied upon advancement of conjunctiva up to $1 \mathrm{~mm}$ behind limbus using $8 / 0$ sutures.

\section{Results}

33 eyes of 30 patients included after following exclusion criteria. All were undergone simple pterygium excision (Figure 2) under local anesthesia ( $2 \%$ lidocaine injection), $1 / 2 \mathrm{cc}$ lidocaine injected subconjunctivally as well as topical alcain eye drops were used before and during surgery. Excision of pterygium done using conjunctival scissors, 15 no blade being used for anterior keratectomy. Excision and corneal scraping followed by advancement of conjunctiva up till $1 \mathrm{~mm}$ behind the limbus with the help of 2sutures of 8/0vicryl. Daily dressing was used with antibiotic steroid combination drops and ointment along with mydriatic eye drops till corneal stain becomes negative i.e mostly on 3rd postoperative day. Patients were kept on sodium hyaluronate and antibiotic steroid combination drops 6hourly and all patients followed except 2 who showed poor compliance, weekly for I month then monthly for more than 1year.
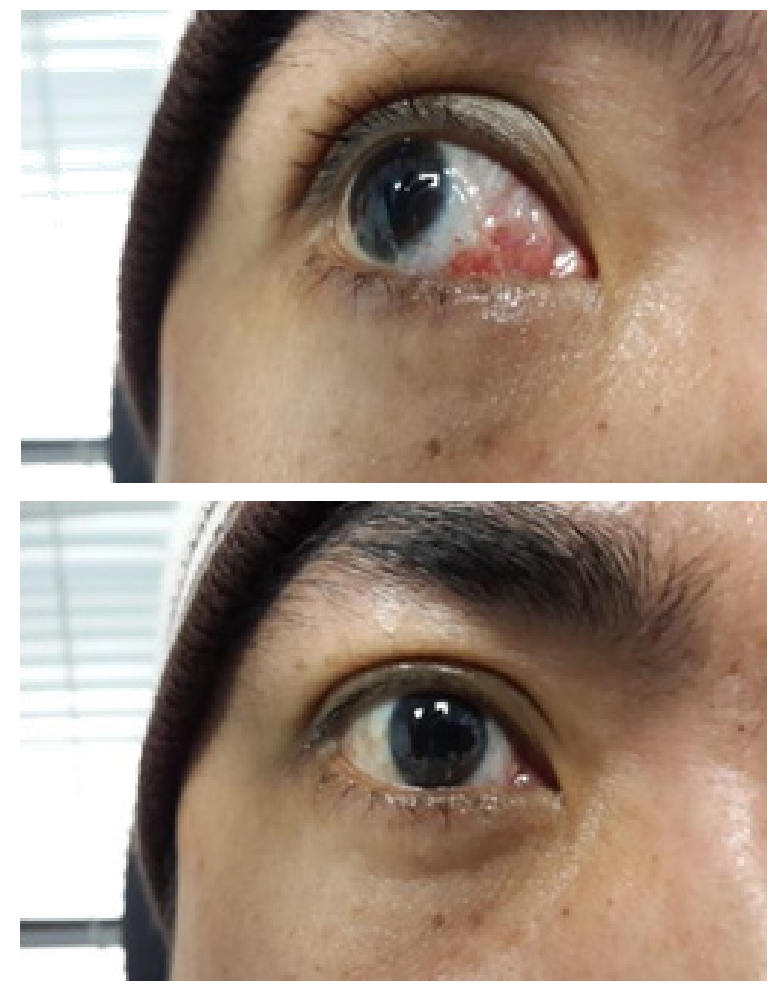

Figure 2 Postoperative follow up after 2 weeks for right pterygium excision.

We did not use cautry, any adjunctive therapy i.e irradiation, mitomycin $\mathrm{C}$ or conjunctival auto graft. We only relied upon simple excision of pterygium with advancement of conjunctiva up to $1 \mathrm{~mm}$ behind limbus using 2 sutures of $8 / 0$ vicryle. Out of 33 only $2(6.06 \%)$ patients suffered with recurrence reason was poor compliance 
regarding the use of medicines (Table 4). One got recurrence after 3 months and other after 8months. 31eyes were not shown any recurrence up till now.

Table 4 Poor compliance regarding the use of medicines

\begin{tabular}{lll}
\hline No. of eyes & No. of recurrence & Percentage $\%$ \\
\hline 33 & 2 & $6.06 \%$ \\
\hline
\end{tabular}

\section{Discussion}

This study which includes 33 eyes of 30 patients carried out between January 2014 to December 2015. Though all the measures like preoperative, during as well as post operative were same as described in material and methods. I used simple excision of pterygium with advancement of conjunctiva up to $1 \mathrm{~mm}$ behind the limbus with the help of 2 sutures of 8/0vicryle. Only 2 patients reported recurrence one after months and another one after 8 months otherwise remaining 30 eyes are without any recurrence even after 15 months of follow up same was reported by Kenyan et al. in their study but with conjunctival autograft, ${ }^{12}$ pterygium surgery is not without complications such as irregular astigmatism, extraocular motility restriction, symblepharon formation..$^{13}$ but in our practice no such complications encountered. Recurrence rate after Bare sclera technique alone (30 to $70 \%),{ }^{14}$ adjunctive treatment with beta irradiation after bare slera technique was $(0.5$ to $10 \%),{ }^{15}$ and with autograft was $(5.3 \%),{ }^{16}$ Ashok et al.. ${ }^{17}$ reported $(5.7 \%)$ almost same rate as in our study but another study conducted by lewallen, shows recurrence rate as high as $(21 \%)$ even after autograft. ${ }^{18}$ Eva et al. ${ }^{19}$ reported $(14 \%)$ recurrence rate while Fahmi et al. ${ }^{20}$ reported (13.3\%) after conjunctival autograft. Different studies showed that even after application of mitomycin C after excision had recurrence rates i.e 19\% Maning et al. $.^{21,22} 10.5 \% .^{23}$ Sharma et al. ${ }^{24,25}$ also compared the results but statistically not better than others. So our technique has results far better and can be compared with autografting, MMC and bare sclera technique.

\section{Conclusion}

Despite different management options are available but we found this technique (simple pterygium excision with advancement of conjunctiva) was very simple, easy and time saving with very less chances of recurrence.

\section{Acknowledgments}

None.

\section{Conflicts of interest}

Author declares there are no conflicts of interest.

\section{References}

1. Wong AK, Rao SK, Leug At, et al. Inferior Limbal-Conjunctival autograft transplantation for recurrent pterygium. Indian $J$ of Ophthalmol. 2000;48(1):21-24.

2. Taylor HR, West SK, Rosenthal FS, et al. Corneal changes associated with chronic UV irradiation. Arch Ophthalmol. 1989;107(10):14811484 .

3. Coroneo MT. Pterygium as an early indicator of ultraviolet insolation: a hypothesis. Br J Ophthalmol. 1993;77(11): 734-739.

4. Nakaishi H, Yamamoto M, I shida M, et al. Pingueculae and pterygia in motorcycle policeman. Ind Health. 1997;35(3): 325-329.
5. Norn M, Franck C. Long-term changes in the outer part of the eye in welders. Prevelence of spheroid degeneration, pinguecula, pterygium, and corneal cicatrices. Acta Ophthalmol (Copenh). 1990;69(3):382386.

6. Klintworth G, Cummings T. The eye and ocular adnexa. In: Stacey Mills (Ed.), Sternberg's Diagnostic Surgical Pathology. $5^{\text {th }}$ edn. ISBN 978-0-7817-7942-5.

7. Gulani A, Dastur YK. Simultaneous pterygium and cataract surgery. $J$ Postgrad Med. 1995;41(1):8-11.

8. Pterygium: MedlinePlus Medical Encyclopedia. 2016.

9. Pterygium Workup: Imaging Studies, Procedures. 2016.

10. Mackenzie FD, Hirst LW, Battistutta D, et al. Risk Analysis in the Development of Pterygia. Ophthalmology. 1992;99(7):1056-1061.

11. Lee GA, Hirst LW, Sheehan M. Knowledge of Sunlight Effects on the Eyes and Protective Behaviours in the General Community. Ophthalmic Epidemiology. Ophthalmic Epidemiol. 1994;1(2): 67-84.

12. Unitomo N, Nori S. Studies on pterygium. Part IV. A treatment of pterygium by mitomycin C instillation. Nippon 33 Ganka Gakkai Zasshi. 1963;67:601-607.

13. Shimazaki J, Shinozaki N, Tsubota K. Transplantation of amniotic membrane and limbal autograft for patients with recurrent pterygium associated with symblepharon. Br J Ophthalmol. 1998;82(3): 235-240.

14. Youngson RM. Recurrence of pterygium after excision. Br JOphthalmo. 1972; 56(2):120-125.

15. MacKenzie FD, Hirst LW, Kynaston B. Recurrence rate and complications after beta irradiation for pterygia. Ophthalmology. 1991;98:1776-1781.

16. Arssano D, Michaeli-Cohen A, Loewenstein A. Excision of rpterygium and conjunctival autograft. Isr Med Assoc J. 2002;4:1097-1100.

17. Narsani AK, Jatoi SM, Khanzada MA, et al. Recurrence of pterygium with conjunctival autograft verses mitomycin C. Pak J Ophthalmol. 2008;24(1): 29-33.

18. Lewallen S. A randomised trial of conjunctival autografting for pterygium in the tropics. Ophthalmology. 1989;96(11):1612-1614.

19. Riordan-Eva P, Kielhorn I, Ficker LA, et al. Conjunctival autografting in the surgical management of pterygium. Eye (Lond). 1993;7( $\mathrm{Pt} 5$ ): $634-638$.

20. Fahmi MS, Sayed J, Ali M.After removal of Pterygium role of Mitomycin and conjunctival autograft. Ann Abbasi Shaheed Hosp Karachi Med Dent Coll. 2005;10(2):757-761.

21. Lam DS, Wong AK, Fan DS, et al. Intraoperative mitomycin $\mathrm{C}$ to prevent recurrence of pterygium after excision: a 30-month follow-up study. Ophthalmology. 1998;105(5):901-904.

22. Manning CA, Kloess PM, Diaz MD, et al. Intraoperative mitomycin in primary pterygium excision. A prospective, randomized trial. Ophthalmology. 1997;104(5):844-848.

23. Tseng SC. Concept and application of limbal stem cells. Eye. 1989;3(Pt 2):141-157.

24. Ma DH, See LC, Liau SB, et al. Amniotic membrane graft for primary pterygium: comparison with conjunctival autograft and topical mitomycin C treatment. Br J Ophthalmol. 2000;84(9):973-978.

25. Sharma A, Gupta A, Ram J, et al. Low-dose intraoperative mitomycin-C versus conjunctival autograft in primary pterygium surgery: long term follow-up. Ophthalmic Surg Lasers. 2000;31(4):301-307. 